\title{
Morbidity compression: a promising and well-established concept?
}

\author{
Siegfried Geyer
}

Received: 26 June 2016/ Accepted: 29 June 2016/Published online: 21 July 2016

(c) Swiss School of Public Health (SSPH+) 2016

In the 1980s, Fries formulated the morbidity compression hypothesis (Beltran-Sanchez et al. 2014). It states that due to improved prevention and better living conditions, the time spent in a state of disease and disability will be compressed towards the end of life. As a consequence, healthy life years will be gained. In the recent years it has received increasing attention within the context of demographic aging.

Recently, this journal published a paper on morbidity compression in Spain (Walter et al. 2016). The report is remarkable in two ways: the focus is on specific diseases, and the authors have used nationwide registry data. The findings were not affected by health-related nonresponse that occurs in surveys what may lead to an overestimation of population health (Hoffmann et al. 2004). However, the choice of morbidity compression as the guiding concept was a good one as it touches a number of public health issues: it contributes to the discussion whether retirement age can be shifted upwardly. Combined with findings from health inequality studies, it will have to be decided whether this applies to entire populations or only to particular groups with high or low health strain. In the latter case a consistent retirement age for all will be untenable. In the area of healthcare it will influence decisions on how and where to allocate medical care and what types of specialists will be needed in the decades to come. Consequences of morbidity compression will even reach city planning and

This comment refers to the article available at doi:10.1007/s00038-016-0829-5.

S. Geyer $(\bowtie)$

Medical Sociology Unit, Hannover Medical School,

Carl-Neuberg-Str. 3, 30625 Hannover, Germany

e-mail: geyer.siegfried@mh-hannover.de architecture when it comes to decide whether more retirement homes shall be built or whether it might rather be better to create housing environments that are promoting and preserving the activity resources of the elderly.

Fries formulated his hypothesis with chronic conditions and disability in mind (Fries 1985). In the meantime it was extended to specific diseases (Beltran-Sanchez et al. 2014), linked with healthy aging (Van Oyen et al. 2013), and with findings on cognitive reserve (Laditka and Laditka 2014). It appears that morbidity compression is a highly relevant topic where links between research and application are rather obvious and immediate. Investments into this area should be rewarded with findings equally relevant to researchers, practitioners, and policy makers. Against the backdrop of such favorable prospects one may lose sight of Fries' formulations being rather unspecific and that open questions remain unresolved. Some will be discussed below.

Fries' studies used impairments and general health as outcomes. As morbidity compression is a time- related concept, it is essential that outcomes are properly dated and diagnosed. For subjective health and functional impairments this is rather difficult to accomplish as they are evolving slowly over time. They are consisting of an accumulation of many small health changes with improvements and deteriorations fluctuating over time, thus making precise onset dates difficult to determine (Kaplan 1991). If longer time periods are considered and marked changes are occurring, it may be possible to examine whether morbidity compression is present. If shorter observation periods are covered and if small changes are expected, conclusions may only be made under uncertainty.

It may thus be a better approach to study specific diagnoses, such as myocardial infarction, stroke or 
diabetes. In spite of these diseases being among the most frequent ones in industrialized countries, their absolute numbers in populations are relatively low. This leads to the necessity of surveying large samples, and the situation is further complicated by health-related nonresponse, i.e., the higher the impairment due to disease, the more likely it is that subjects will not participate in surveys. The use of registry data may be a way out, but it has to be considered that changes of codes (i.e., from CD-9 to ICD-10) may lead to erroneous conclusions about incidences.

Besides these rather technical issues, the concept itself needs clarification. This refers to the question on how specific diseases are associated with total morbidity and mortality. In any case, they should not be linked with specific causes of death as this might lead to erroneous conclusions. Applied to the example of cancers, even if onset age is postponed upwardly, shorter time periods between disease onset and death do not indicate morbidity compression. Rather, this should indicate a qualitative decline of medical care. It also needs to be considered if diseases are developing into different directions. This is the case with diabetes where onset age is decreasing, and with myocardial infarction that is moving into the opposite direction. Research on specific diseases may rather be interpreted as particular cases contributing to general morbidity compression or to one of the competing concepts dealing with morbidity development, i.e., morbidity expansion or the dynamic equilibrium (Geyer 2015). In the same way, a particular disease contributes to the development of mortality only at population level.
Several methodological and conceptual issues will have to be resolved for making morbidity compression a fruitful concept. This is not to be interpreted in a negative, but rather in a positive way as it opens up new fields for scientific activities.

\section{References}

Beltran-Sanchez H, Razak F, Subramanian SV (2014) Going beyond the disability-based morbidity definition in the compression of morbidity framework. Glob Health Action 7:24766

Fries JF (1985) The compression of morbidity. World Health Forum 6:47-51

Geyer S (2015) Die Morbiditätskompressionsthese und ihre Alternativen. Das Gesundheitswesen 77:442-446

Hoffmann W, Terschüren C, Holle R, Kamtsiuris P, Bergmann M, Kroke S, Sauer S, Stang A, Latza U (2004) Zum Problem der Response in epidemiologischen Studien in Deutschland (Teil II). Das Gesundheitswesen 66:482-491

Kaplan GA (1991) Epidemiologic observations on the compression of morbidity: evidence from the Alameda County Study. J Aging Health 3(2):155-171

Laditka SB, Laditka JN (2014) More education may limit disability and extend life for people with cognitive impairment. Am J Alzheimer's Dis Other Dement 29(5):436-447

Van Oyen H, Nusselder WJ, Jagger C, Kolip P, Cambois E, Robine J-M (2013) Gender differences in healthy life years within the EU: an exploration of the "health-survival" paradox. Int J Public Health 58(1):143-155

Walter S, Beltran-Sanchez H, Regidor E, Gomez-Martin C, DelBarrio JL, Gil-de-Miguel A, Subramanian SV, Gil-Prieto R (2016) No evidence of morbidity compression in Spain: a time series study based on national hospitalization records. Int $\mathbf{J}$ Public Health. doi:10.1007/s00038-016-0829-5 